\title{
Micropropagation of zygotic embryos from genetically diverse almond seedling orchards in eastern Morocco
}

\author{
Souhayla Kodad ${ }^{1, *}$, Reda Melhaoui ${ }^{1}$, Mohamed Addi ${ }^{1}$, Christophe Hano ${ }^{2}$, Nargis Sahib ${ }^{1}$, Ahmed Elamrani $^{1}$, Malika Abid $^{1}$, \\ and Aatika Mihamou ${ }^{1}$ \\ ${ }^{1}$ Laboratoire d'Amélioration des Productions Agricoles, Biotechnologie \& Environnement, (LAPABE), Faculté des sciences, Université \\ Mohammed Premier, Oujda, Morocco \\ ${ }^{2}$ Laboratoire de Biologie des Ligneux et des Grandes Cultures (LBLGC), INRAE USC1328, Université d'Orléans, 21 rue de Loigny la \\ Bataille, F-28000 Chartres, France
}

\begin{abstract}
Numerous studies on perennial crops have shown that almond has a low tolerance to climate change, which led to detailed study for its adaptation by focusing on selecting heat-tolerant almond varieties. The long period of perennial agriculture creates particular challenges in a changing climate. The risk complicates the choice of a variety that the best variety for the current climate may be poorly suited for future climates. Hence the interest of having a large variability of tolerant genotypes. In the eastern Mediterranean region of Morocco, seedling almond trees are largely grown, which created an important gene pool, both for breeding programs and the selection of superior genotypes adapted to difficult pedo-climatic conditions. For the conservation of crop biodiversity in these almond groves, micropropagation is considered a feasible technique for producing and regenerating superior planting materials. Zygotic embryos of several local ecotypes of the almond native population known as "Beldi" were cultivated on Murashige and Skoog (MS) medium supplemented with different concentrations and combinations of auxins and cytokinins. The results showed multiple shoot initiation from zygotic embryos on MS medium containing $1 \mathrm{mg} / \mathrm{L}$ of 6-Benzylaminopurine (BAP) combined with $0.5 \mathrm{mg} / \mathrm{L}$ of Indole butyric acid (IBA). A high rooting rate was obtained on a half-strength MS medium supplemented with $1 \mathrm{mg} / \mathrm{L}$ of IBA.
\end{abstract}

\section{Introduction}

In Morocco, the almond trees are grown in several regions from North to South, under different environmental conditions, mainly in rain-fed areas with poor soils that receive little attention from farmers. The resulting variability of environment and climate has evolved into a wide variety of almond genotypes in each production region, as about $50 \%$ of the almond trees grown in Morocco are derived from seedlings [1]. Traditional almond cultivation used open-pollinated seedlings [2], which, with self-incompatibility, produced very high heterozygosity in this species [3]. This significant variability has provided a functional genetic pool for the evolution of almonds, allowing each growing region to select almond cultivars well adapted to the region [4]. The eastern region of Morocco was recently supported by the Belgian development agency "BTC" through the project "PROFAO *" to plant 6000 ha of almond trees and improve the post-harvest value chain, including the evaluation of almonds and derived products. Several studies have been undertaken to evaluate the genetic diversity and quality of nuts in the Moroccan almond population using morphological and phenological characterization $[5,6]$. However, studies on the in vitro multiplication of these almonds have, until now, never been done before.

Climate has a significant impact on temperate fruit and nuts, mainly in vulnerable regions like the Mediterranean, since the lack of chilling may directly affect perennial crops' yield. The currently focused studies on the selection of late-flowering cultivars and the temperature increase associated with climate change may cause considerable damages in the future, such as reducing yield performance and quality of almonds since several studies have revealed the chill decline caused by climate change $[7,8]$. Phenology is a significant determinant of the final almond yield [9] and plays a critical role in the processes involved. Hence, the importance of maintaining variability in almond crops in each production area seems to be a helpful tool for an adaptation strategy to future climate conditions, allowing sustainable production in variable weather conditions. Moreover, traditional almond plantations in eastern Morocco show a better richness in tocopherols than the other four introduced varieties cultivated in the same region (Fournat, Marcona, and the couple Ferragnes/Ferraduel) [10]

By in vitro culture, this study aimed to protect the variability of traditional almond plantations in eastern Morocco and will lead to a detailed study to preserve this

\footnotetext{
* Corresponding author: souhaila.kodad@gmail.com
} 
exciting ecotype by proving its genetic variability for its rescue and preservation.

\section{Materiels and methods}

\subsection{Plant material and explant preparation}

In this study, zygotic embryos of several local genotypes were collected from old trees of almond growing in four areas in the North-East region of Morocco. These explants were surface-sterilized by immersion in a $40 \%$ (v/v) commercial bleach solution ( $\mathrm{NaOCI}$ ) for $20 \mathrm{~min}$ after presterilization processes, which included washing with tap water for 3-5 min and then rinsing with $70 \%(\mathrm{w} / \mathrm{v})$ ethanol for $30 \mathrm{~s}$. Later, the mature seeds were rinsed with sterilized water five times for $5 \mathrm{~min}$ each.
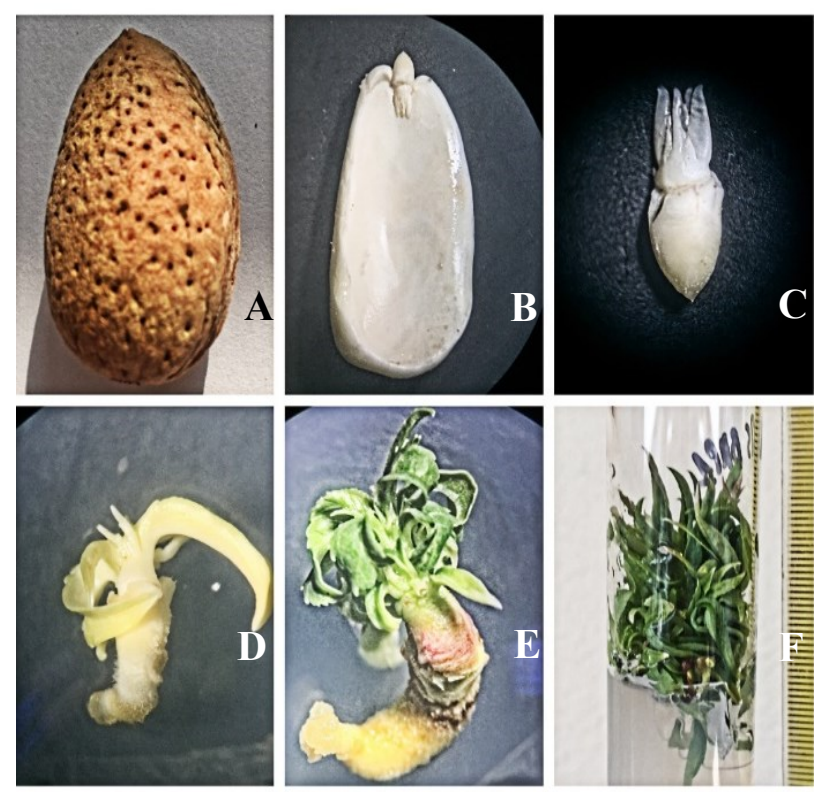

Fig. 1. Culture of zygotic embryos: (A) Beldi almond with shell (B) Half almond (C) Isolated zygotic embryo culture on MS medium + BAP 1mg/L (D) zygotic embryo after one week in the dark (E) zygotic embryo after been exposed to the light, (F) development of a cluster of shoots after 2 weeks.

\subsection{Establishment of zygotic embryos in vitro culture}

After sterilization, the zygotic embryos were isolated from the mature seeds before being inoculated into the Murashige and Skoog (MS) basal medium [11] supplemented with $1 \mathrm{mg} / \mathrm{L}$ of 6-Benzyl-aminopurine (BAP) or Kinetine (KIN) associated or not with $0.5 \mathrm{mg} / \mathrm{L}$ Indole butyric acid (IBA) (Fig. 1b, c). One week after culture in the dark (Fig. 1d), the germinated almond embryos were exposed to the light, and after four weeks of culture, they produced actively growing shoots (Fig. $1 \mathrm{e}, \mathrm{f}$ ). In the first stage, for in vitro proliferation of axenic germinated explants with at least an apical shoot, the explants were aseptically cut and cultured in a hormonefree MS medium. The newly formed shoots were separated and used for the induction of in vitro rooting.

\subsection{Rooting and acclimatization}

For rooting experiments, two different media (Halfstrength MS and Heller) containing different concentrations of IBA $(0,0.5$, and $1 \mathrm{mg} / \mathrm{L})$ were tested (Table 2). The media were supplemented with $3 \%$ sucrose $(\mathrm{w} / \mathrm{v})$ and solidified with agar $(0,7 \%, \mathrm{w} / \mathrm{v}$, Agar-Agar, sigma) adjusted to $\mathrm{pH} 5.7$ before autoclaving $\left(120^{\circ} \mathrm{C}\right.$ for $20 \mathrm{~min})$. Plant growth regulators were added to the medium before the adjustment of $\mathrm{pH}$ and sterilization. The cultures were maintained at $25 \pm 2^{\circ} \mathrm{C}$ with a $16 \mathrm{~h}$ photoperiod (40 $\mu \mathrm{mol} \mathrm{m-2} \mathrm{s-1)} \mathrm{provided} \mathrm{by} \mathrm{mercury}$ fluorescent lamps. In vitro rooted shoots were washed in running water before being potted in a 1:1:1 mixture of perlite, sand, and soil. Plantlets were covered with plastic cups to maintain relative humidity for 3-4 weeks before transfer into the growth room. The growth room was illuminated by mercury fluorescent lamps $(400 \mathrm{~W})$. The plants were irrigated every 2-3 days with water and, after 38 days, were successfully adapted to the in vivo condition.

\subsection{Statistical analysis}

The experimental design used in this study was completely randomized. Analysis of Variance (ANOVA) analyzed all data, and Duncan's multiple range tests were performed to analyze shoot number and shoot length rates. Likelihood ratio $\chi 2$-test (G-test) was used to analyze rooting frequencies. Living sterile shoots and roots constituted the basis of the statistical analysis. For all comparisons, statistical significance was considered at $\mathrm{P}$ B 0.05 .

\section{Results and discussion}

\subsection{Effect of plant growth regulators on zygotic embryos in vitro culture}

In the first experiment, several zygotic embryos (B1, B2, $\mathrm{B} 3$, and $\mathrm{B} 4)$ isolated in vitro conditions were cultured on MS medium supplemented with BAP or KIN either alone or in combination with IBA or NAA. Germination rate, as well as the number and the length of shoots, were recorded (Table 1). The effect of type of cytokinin on the culture initiation of zygotic embryos isolated from mature seeds of almonds significantly affects the frequencies of embryos germination. However, either in BAP or KIN, high germination rates were obtained, ranging between 70.5 and $93.05 \%$ (Table 1). The presence of BAP has a higher effect than KIN according to the number and the length of new shoots formed since the number of shoots was between 3 and 4 in the presence of BAP. While with KIN, it was between 2 and 3 , and for the length of shoots, it ranged from 2,5 to $3,1 \mathrm{~cm}$ in the presence of BAP, while with KIN, it was 2 to $2,4 \mathrm{~cm}$. For most genotypes, the combination of $1 \mathrm{mg} / \mathrm{L}$ of BAP or KIN with $0.5 \mathrm{mg} / \mathrm{L}$ IBA or NAA resulted from significant differences. Indeed, the best germination rates were obtained with B3 genotype on MS medium supplemented with $1 \mathrm{mg} / \mathrm{L}$ BAP and 0.5 $\mathrm{mg} / \mathrm{L}$ IBA $(93.05 \%)$, while the maximum number of 
shoots was obtained in the presence of BAP at $1 \mathrm{mg} / \mathrm{L}$ combined with IBA at $0.5 \mathrm{mg} / \mathrm{L}(9$ shoots) and a substantial length was also recorded at the same concentration $(3.1 \mathrm{~cm})$. While in the presence of NAA associated with $\mathrm{KIN}$, the highest germination rates $(90.2 \%)$ and length $(3.0 \mathrm{~cm})$ were obtained with the B4 genotype, and the maximum number of shoots (6.43) was recorded for the B1 genotype at the same concentrations.

Table 1. The germination rate, the number and length of shoots of isolated zygotic embryos according to the concentrations of different phytohormones.

\begin{tabular}{|c|c|c|c|c|c|c|c|}
\hline \multirow[t]{2}{*}{$\begin{array}{c}\text { Gen } \\
\text { otyp } \\
\text { es }\end{array}$} & \multicolumn{4}{|c|}{$\begin{array}{c}\text { Plant Growth } \\
\text { Regulators (mg/L) }\end{array}$} & \multirow[t]{2}{*}{$\begin{array}{c}\text { Germina } \\
\text { tion rate } \\
(\%)\end{array}$} & \multirow[t]{2}{*}{$\begin{array}{c}\text { Average } \\
\text { shoot } \\
\text { numbers }\end{array}$} & \multirow{2}{*}{\begin{tabular}{|c} 
Average \\
shoot \\
Lengths \\
(cm) \\
\end{tabular}} \\
\hline & BAP & KIN & NAA & IBA & & & \\
\hline \multirow{6}{*}{ B1 } & 1 & 0 & 0 & 0 & $84.07 \mathrm{~g}$ & 3.10 & $2.2 \mathrm{f}$ \\
\hline & 1 & 0 & 0.5 & 0 & $83.1 \mathrm{~h}$ & $4.0 \mathrm{i}$ & $2.5 \mathrm{c}$ \\
\hline & 1 & 0 & 0 & 0.5 & $91.02 b$ & $5.2 \mathrm{f}$ & $3.1 \mathrm{a}$ \\
\hline & 0 & 1 & 0 & 0 & $78.5 \mathrm{k}$ & $2.33 p$ & $2.4 \mathrm{~d}$ \\
\hline & 0 & 1 & 0.5 & 0 & $79.29 \mathrm{j}$ & $6.43 b$ & $1.5 \mathrm{i}$ \\
\hline & 0 & 1 & 0 & 0.5 & $89.2 \mathrm{e}$ & $4.0 \mathrm{i}$ & $2.0 \mathrm{~h}$ \\
\hline \multirow{6}{*}{ B2 } & 1 & 0 & 0 & 0 & $80.04 \mathrm{i}$ & $3.67 \mathrm{j}$ & $3.1 \mathrm{a}$ \\
\hline & 1 & 0 & 0.5 & 0 & 77.51 & $5.4 \mathrm{~d}$ & $2.4 \mathrm{~d}$ \\
\hline & 1 & 0 & 0 & 0.5 & $85.28 \mathrm{f}$ & $6.0 \mathrm{c}$ & $1.5 \mathrm{i}$ \\
\hline & 0 & 1 & 0 & 0 & $79.2 \mathrm{j}$ & $3.17 \mathrm{n}$ & $2.0 \mathrm{~h}$ \\
\hline & 0 & 1 & 0.5 & 0 & $81.03 \mathrm{i}$ & $5.4 \mathrm{~d}$ & $2.3 \mathrm{e}$ \\
\hline & 0 & 1 & 0 & 0.5 & $90.17 d$ & 3.31 & $2.5 \mathrm{c}$ \\
\hline \multirow{6}{*}{ B3 } & 1 & 0 & 0 & 0 & $80.03 \mathrm{i}$ & $4.0 \mathrm{i}$ & $2.3 \mathrm{e}$ \\
\hline & 1 & 0 & 0.5 & 0 & $90.12 \mathrm{~d}$ & $5.2 \mathrm{f}$ & $2.5 \mathrm{c}$ \\
\hline & 1 & 0 & 0 & 0.5 & $93.05 \mathrm{a}$ & $9.4 \mathrm{a}$ & $3.1 \mathrm{a}$ \\
\hline & 0 & 1 & 0 & 0 & $70.5 \mathrm{~m}$ & $2.12 \mathrm{q}$ & $2.4 \mathrm{~d}$ \\
\hline & 0 & 1 & 0.5 & 0 & $79.39 \mathrm{j}$ & $3.5 \mathrm{k}$ & $1.5 \mathrm{i}$ \\
\hline & 0 & 1 & 0 & 0.5 & $84.05 \mathrm{~g}$ & $5.1 \mathrm{~g}$ & $2.3 \mathrm{e}$ \\
\hline \multirow{6}{*}{ B4 } & 1 & 0 & 0 & 0 & $79.34 \mathrm{j}$ & $2.02 \mathrm{~s}$ & $2.5 \mathrm{c}$ \\
\hline & 1 & 0 & 0.5 & 0 & $84.05 \mathrm{~g}$ & $4.6 \mathrm{~h}$ & $2.3 \mathrm{e}$ \\
\hline & 1 & 0 & 0 & 0.5 & $90.1 \mathrm{~d}$ & $3.2 \mathrm{~m}$ & $2.5 \mathrm{c}$ \\
\hline & 0 & 1 & 0 & 0 & $80.07 \mathrm{i}$ & $2.04 \mathrm{r}$ & $2.1 \mathrm{~g}$ \\
\hline & 0 & 1 & 0.5 & 0 & $90.2 b$ & $5.3 \mathrm{e}$ & $3.0 \mathrm{~b}$ \\
\hline & 0 & 1 & 0 & 0.5 & $86.1 \mathrm{ef}$ & $6.8 \mathrm{~b}$ & $2.6 \mathrm{c}$ \\
\hline
\end{tabular}

Different lowercase letters above any two columns indicate that the means are statistically different at $\mathrm{P} \leq 0.05$ according to the Duncan multiple tests. Data were taken two weeks after culture.

Previous studies have shown that cytokinins alone or auxins are essential for explant proliferation [12]. Our results agree with those obtained in other research where the best shoot growth and proliferation rate of the commercial cultivars of almond (Nonpareil and Texas) were recorded in MS medium containing $1.0 \mathrm{mg} / \mathrm{L}$ of BAP [13]. Similar results were reported by Tabachnik and Kester (1977) [14], showing that the use of BAP in the shoot multiplication was an absolute necessity and the reduction of BAP concentration inhibited new axillary shoot formation. In comparison, we added IBA at the concentration of $0.5 \mathrm{mg} / \mathrm{L}$ to the medium to obtain significantly higher results with a maximum number of shoots (9) and significant lengths $(3 \mathrm{~cm})$.

\subsection{Rooting and acclimatization of zygotic embryos}

For rooting experiments, two different media (Halfstrength MS and Heller) containing different concentrations of IBA $(0.5,1$, and $1.5 \mathrm{mg} / \mathrm{L})$ were tested (Table 2).

Table 2. Rooting of the Beldi ecotype in various media and different concentrations of IBA.

\begin{tabular}{|c|c|c|c|c|}
\hline \multicolumn{2}{|c|}{ Rooting media } & \multirow{2}{*}{$\begin{array}{l}\text { Rooting } \\
\text { rate } \%\end{array}$} & \multirow{2}{*}{$\begin{array}{c}\text { Roots } \\
\text { number }\end{array}$} & \multirow{2}{*}{$\begin{array}{c}\text { Roots } \\
\text { length } \\
(\mathrm{cm})\end{array}$} \\
\hline Media & $\begin{array}{c}\text { IBA } \\
(\mathrm{mg} / \mathrm{L})\end{array}$ & & & \\
\hline \multirow{3}{*}{$\begin{array}{c}\text { Half- } \\
\text { strength } \\
\text { MS }\end{array}$} & 0.5 & $21,12 \mathrm{e}$ & $1.0 \mathrm{~d}$ & $1.0 \mathrm{c}$ \\
\hline & 1.0 & $62,43 a$ & $6.0 \mathrm{a}$ & $2.3 \mathrm{a}$ \\
\hline & 1.5 & $43,71 b$ & $2.0 \mathrm{~b}$ & $1.7 \mathrm{~b}$ \\
\hline \multirow{3}{*}{ Heller } & 0.5 & $15,03 \mathrm{f}$ & $1.0 \mathrm{~d}$ & $0.3 \mathrm{~b}$ \\
\hline & 1.0 & $28 \mathrm{c}$ & $2.0 \mathrm{~b}$ & $0.5 \mathrm{~d}$ \\
\hline & 1.5 & $25,1 d$ & $1.5 \mathrm{c}$ & $1.4 \mathrm{~b}$ \\
\hline
\end{tabular}

Different lowercase letters above any two columns indicate that the means are statistically different at $\mathrm{P} \leq 0.05$ according to the Duncan multiple tests. Data were taken six weeks after culture.

The half-strength MS with $1 \mathrm{mg} / \mathrm{L}$ IBA was found to be the best medium for in vitro rooting of the "Beldi" ecotype because it gives the highest rooting rate $(62,43 \%)$ and produces the maximum number of roots (6), and it had significant lengths $(2.3 \mathrm{~cm})$ (Table 2$)$.

The use of auxins for in vitro rooting has also been reported by other studies; in a previous study on GF677, the highest rooting percentage was found on a medium containing $1 \mathrm{mg} / \mathrm{L}$ of IBA. It has also been reported that IBA induces better lateral rooting than indole acetic acid (AIA) [15], [16].

\section{Conclusion}

In vitro culture techniques could be an essential tool for the production and regeneration of superior planting materials with a high tolerance to climate-changing, and it could be a unique solution for the conservation of crop biodiversity in almond groves by eliminating various diseases and increasing the variability of tolerant genotypes to maintain a sustainable production in the current climate in the future ones.

In this study, the regeneration of different explants was significantly affected by the genotypes and the different plant growth regulators combinations and concentrations. The results showed multiple shoot initiation from embryos on MS medium containing $1 \mathrm{mg} / \mathrm{L}$ BAP combined to $0,5 \mathrm{mg} / \mathrm{L}$ IBA and the best in vitro rooting of the "Beldi" ecotype was obtained in a halfstrength MS medium supplemented with $1 \mathrm{mg} / \mathrm{L}$ IBA. 


\section{References}

1 A. lansar. H.Azoulay,D. E. Kester, II Int Sym P A. 96-100 (1998)

2 K. Sorkheh, S. Kiani, A. Sofo. $F d$ ch, 212, 58-64 (2016)

3 R. Socias I Company, A. J. Felipe, J. Hortic. Sci. 67, 313-317 (1992)

4 T. M Gradziel,. A B P. Cabi.. (2017).

5 A. Mahhou, F. G. Dennis,Hort Tech, 2, 4, 488-492 (1992)

6 A. Lansari, A. F. Iezzoni, D. E. Kester, Euph, 78, 1, 27-41 (1994)

7 A. Rodríguez, D. Pérez-López, E. Sánchez, A. Centeno, I. Gómara, A. Dosio, Nat. Hazards Earth Syst. Sci. 19, 1087-1103 (2019)

8 R. Darbyshire, E. W. R. Barlow, L. Webb, I. Goodwin in (2014) XXIX Int. Hortic. Congr. Hortic. Sustain. Lives, Livelihoods Landscapes 1130, 11-18. (2014)

9 I. J. Lorite, J. M. Cabezas-luque, O. Arquero, C. Gabaldón-leal, C. Santos, A. Rodríguez Agric. For. Met. 294, 108142 (2020)

10 R. Melhaoui, M. L. Fauconnier, M. Sindic, M. Addi, M. Abid, A. Mihamou, A. Elamrani, N Symp App Bio Sc, (2018)

11 T. Murashige, Symp. Tissue Cult. Hortic. Purp. 78, 17-30 (1977)

12 F. Sadeghi, A. Yadollahi, M. J. Kermani, M. Eftekhari, J. Genet. Eng. Biotechnol. 13, 19-23 (2015)

13 S. Gürel, Y. Gülşen, Turk. J. Bot., 22, 363-373 (1998)

14 L. Tabachnik, D. E. Kester (1977)

15 M. N. Nas, Y. BÖLEK, N. Sevgin, Turk. J. Bot. 1134-1144 (2013)

16 G. J. Klerk, W. Van Der Krieken, J. C. de Jong. Review the formation of adventitious roots: new concepts, new possibilities. $I V C \& D B i o-P l, 35,3$, 189-199 (1999) 